\title{
TITLE:
}

\section{Impacts of growth parameters on deep levels in n-type $4 \mathrm{H}-\mathrm{SiC}$}

\author{
$\operatorname{AUTHOR}(S)$ :
}

Danno, K; Hori, T; Kimoto, T

\section{CITATION:}

Danno, K ... [et al]. Impacts of growth parameters on deep levels in ntype 4H-SiC. JOURNAL OF APPLIED PHYSICS 2007, 101(5): 053709.

\section{ISSUE DATE:}

2007-03-01

URL:

http://hdl.handle.net/2433/50215

\section{RIGHT:}

Copyright 2007 American Institute of Physics. This article may be downloaded for personal use only. Any other use requires prior permission of the author and the American Institute of Physics. 


\title{
Impacts of growth parameters on deep levels in $n$-type $4 \mathrm{H}$-SiC
}

\author{
Katsunori Danno ${ }^{\text {a) }}$ \\ Department of Electronic Science and Engineering, Kyoto University, Kyotodaigaku-katsura, Nishikyo, \\ Kyoto 615-8510, Japan \\ Tsutomu Hori \\ Department of Electronic Science and Engineering, Kyoto University, Kyotodaigaku-katsura, Nishikyo, \\ Kyoto 615-8510, Japan and $R$ \& D Center, NEOMAX Co., Ltd., 2-15-17 Egawa, Shimamoto, Osaka 618- \\ 0013, Japan \\ Tsunenobu Kimoto \\ Department of Electronic Science and Engineering, Kyoto University, Kyotodaigaku-katsura, Nishikyo, \\ Kyoto 615-8510, Japan
}

(Received 31 October 2006; accepted 19 December 2006; published online 9 March 2007)

\begin{abstract}
Deep levels in $n$-type $4 \mathrm{H}$-SiC epilayers have been investigated by deep level transient spectroscopy. The $\mathrm{Z}_{1 / 2}$ and $\mathrm{EH}_{6 / 7}$ centers are dominant in epilayers grown with low $\mathrm{C} / \mathrm{Si}$ ratios during chemical vapor deposition. By increasing the $\mathrm{C} / \mathrm{Si}$ ratio, the $\mathrm{Z}_{1 / 2}$ and $\mathrm{EH}_{6 / 7}$ concentrations are decreased, while an unknown trap (the $\mathrm{UT}_{1}$ center, $E_{c}-1.45 \mathrm{eV}$ ) is introduced. The $\mathrm{Z}_{1 / 2}$ and $\mathrm{EH}_{6 / 7}$ concentrations are not changed by increasing the growth rate from 14 to $23 \mu \mathrm{m} / \mathrm{h}$ at a fixed $\mathrm{C} / \mathrm{Si}$ ratio. By increasing growth temperature from 1550 to $1750{ }^{\circ} \mathrm{C}$, however, the $\mathrm{Z}_{1 / 2}$ and $\mathrm{EH}_{6 / 7}$ concentrations are significantly increased. From these results, the formation of $Z_{1 / 2}$ and $\mathrm{EH}_{6 / 7}$ centers are mainly affected by the $\mathrm{C} / \mathrm{Si}$ ratio and growth temperature rather than the growth rate. These phenomena can be explained with a model that both $\mathrm{Z}_{1 / 2}$ and $\mathrm{EH}_{6 / 7}$ centers are related to a carbon vacancy, which has been recently proposed by the authors. (C) 2007 American Institute of Physics. [DOI: 10.1063/1.2437666]
\end{abstract}

\section{INTRODUCTION}

Silicon carbide $(\mathrm{SiC})$ is an attractive material for realizing high-power, high-temperature, and high-frequency devices, owing to its superior properties such as wide band gap, high breakdown field, high thermal conductivity, and high saturation electron drift velocity. ${ }^{1} 4 \mathrm{H}-\mathrm{SiC}$ has been regarded as the most promising polytype for fabricating vertical-type high-voltage devices, due to higher bulk mobility and smaller anisotropy. To realize $\mathrm{SiC}$ power devices with high blocking voltage of more than several kilovolts, bipolar devices such as pin diodes, thyristors, and insulated gate bipolar transistors possess great promise in terms of lower onresistance owing to the effect of conductivity modulation. ${ }^{2,3}$ Long minority carrier lifetime is required for effective conductivity modulation. Although the lifetime of $\mathrm{SiC}$ epilayers has been investigated by several groups, ${ }^{4-7}$ it does not exceed 1-2 $\mu \mathrm{s}$, which is a-few-orders-of-magnitude smaller than that of high-purity silicon. Since deep levels may play an important role in limiting the carrier lifetime, the concentration should be decreased.

In as-grown $n$-type $4 \mathrm{H}$-SiC epilayers, the $\mathrm{Z}_{1 / 2}\left(E_{c}\right.$ $-0.65 \mathrm{eV})\left(\right.$ Ref. 8) and $\mathrm{EH}_{6 / 7}\left(E_{c}-1.55 \mathrm{eV}\right)$ (Ref. 9) centers are two major deep levels, detected by deep level transient spectroscopy (DLTS). ${ }^{10}$ Their concentrations are decreased by increasing the $\mathrm{C} / \mathrm{Si}$ ratio ${ }^{11,12}$ during chemical vapor deposition (CVD). However, many features remain unknown about formation of the deep levels during CVD growth of $\mathrm{SiC}$.

\footnotetext{
${ }^{a)}$ Electronic mail: k-danno@semicond.kuee.kyoto-u.ac.jp
}

In this work, the authors have tried to clarify the growth parameters $(\mathrm{C} / \mathrm{Si}$ ratio, growth rate, growth temperature, etc.), which affect formation of the deep levels in $n$-type $4 \mathrm{H}-\mathrm{SiC}$. The key issue to reduce trap concentration in conjunction with possible origins is discussed.

\section{EXPERIMENT}

Epitaxial growth was performed on $8^{\circ}$ off-axis $4 \mathrm{H}-\mathrm{SiC}(0001) n^{+}$substrates by horizontal hot-wall CVD in a $\mathrm{SiH}_{4}-\mathrm{C}_{3} \mathrm{H}_{8}-\mathrm{H}_{2}$ system. ${ }^{13}$ Epitaxial growth was performed at $1550-1750{ }^{\circ} \mathrm{C}$ with a typical reactor pressure of 80 Torr. The growth rate was varied in the range from 9.3 to $54 \mu \mathrm{m} / \mathrm{h}$ by changing the $\mathrm{SiH}_{4}$ flow rate from 4 to $20 \mathrm{sccm}$. The $\mathrm{C} / \mathrm{Si}$ ratio was varied from 0.8 to 2.0 by changing the $\mathrm{C}_{3} \mathrm{H}_{8}$ flow rate at a fixed $\mathrm{SiH}_{4}$ flow rate. The flow rate of $\mathrm{H}_{2}$ carrier gas was $10 \mathrm{slm}$. Most epilayers were intentionally doped with nitrogen.

The net donor concentration of epilayers, determined by capacitance-voltage measurement, was in the range from $2.2 \times 10^{14} \mathrm{~cm}^{-3}$ to $1.8 \times 10^{16} \mathrm{~cm}^{-3}$. Nickel was thermally evaporated onto the sample surface as Schottky contacts with a thickness of approximately $70 \mathrm{~nm}$. Ohmic contacts were formed with silver paste on the backside of highly doped $n$-type substrates. Typical diameter of the Schottky contacts was $1500 \mu \mathrm{m}$.

Deep levels were investigated by DLTS in the temperature range from 100 to $700 \mathrm{~K}$. If not specified, the reverse bias was kept at $-5 \mathrm{~V}$, and the pulse voltage applied during the DLTS measurements was $0 \mathrm{~V}$ (pulse height: $5 \mathrm{~V}$ ). The period width of $0.2 \mathrm{~s}$ was employed for all the DLTS mea- 

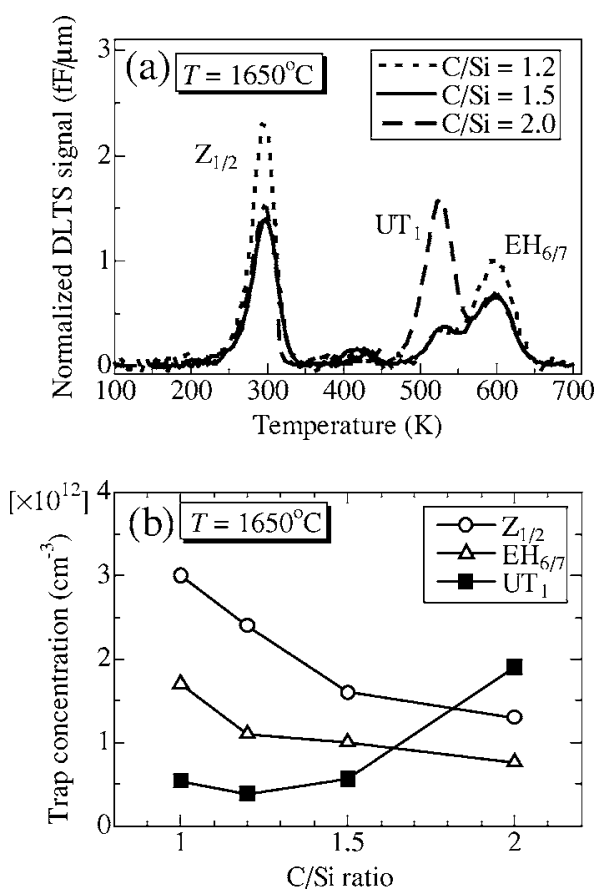

FIG. 1. (a) Normalized DLTS spectra of as-grown $n$-type $4 \mathrm{H}$-SiC epilayers grown at $1650{ }^{\circ} \mathrm{C}$ with various $\mathrm{C} / \mathrm{Si}$ ratios of $1.2,1.5$, and 2.0. The DLTS signals are normalized by depletion layer width. (b) $\mathrm{C} / \mathrm{Si}$ ratio dependence of the $\mathrm{Z}_{1 / 2}, \mathrm{EH}_{6 / 7}$, and $\mathrm{UT}_{1}$ concentrations.

surements performed in this study. A Fourier transform analysis $^{14}$ of the measured transients was employed. A temperature-independent capture cross section was assumed when analyzing the DLTS data. In this article, the trap concentrations are corrected by considering the lambda effect. ${ }^{15}$

\section{RESULTS}

Figure 1(a) shows the DLTS spectra normalized by depletion layer width of the $n$-type $4 \mathrm{H}$-SiC epilayers grown with $\mathrm{C} / \mathrm{Si}$ ratios of $1.2,1.5$, and 2.0. The epilayers were grown with the $\mathrm{SiH}_{4}$ flow rate of $8.0 \mathrm{sccm}$ at $1650{ }^{\circ} \mathrm{C}$. The growth rate and thickness of the samples were almost constant at $24 \mu \mathrm{m} / \mathrm{h}$ and $24 \mu \mathrm{m}$, regardless of the $\mathrm{C} / \mathrm{Si}$ ratio in this range. As shown in Fig. 1(a), two peaks at 295 and 600 $\mathrm{K}$ were dominant in the samples grown with the $\mathrm{C} / \mathrm{Si}$ ratios of 1.2 and 1.5. According to the Arrhenius plot of emission time constant, the capture cross section and activation energy were $2 \times 10^{-14} \mathrm{~cm}^{2}$ and $0.61 \mathrm{eV}$ for the trap at $295 \mathrm{~K}$, and $1 \times 10^{-13} \mathrm{~cm}^{2}$ and $1.54 \mathrm{eV}$ for the trap at $600 \mathrm{~K}$. From the results, these peaks can be assigned to the $\mathrm{Z}_{1 / 2}$ center ${ }^{8}$ and the $\mathrm{EH}_{6 / 7}$ center. ${ }^{9}$ In Fig. 1(b), the dependence of the trap concentrations on the $\mathrm{C} / \mathrm{Si}$ ratio is shown. The trap concentrations were decreased by increasing the $\mathrm{C} / \mathrm{Si}$ ratio and reduced to $1.3 \times 10^{12} \mathrm{~cm}^{-3}\left(\mathrm{Z}_{1 / 2}\right)$ and $7.6 \times 10^{11} \mathrm{~cm}^{-3}\left(\mathrm{EH}_{6 / 7}\right)$ at the $\mathrm{C} / \mathrm{Si}$ ratio of 2.0. Therefore, formation of the $\mathrm{Z}_{1 / 2}$ and $\mathrm{EH}_{6 / 7}$ centers is pronounced under Si-rich conditions.

In the DLTS spectrum of the epilayer grown with a $\mathrm{C} / \mathrm{Si}$ ratio of 2.0, a sharp peak at $500 \mathrm{~K}$ (labeled $\mathrm{UT}_{1}$ ) was observed. According to the Arrhenius plot, the $\mathrm{UT}_{1}$ center is energetically located at $E_{c}-1.45 \mathrm{eV}$. The $\mathrm{UT}_{1}$ concentration was lower than mid $10^{11} \mathrm{~cm}^{-3}$ in epilayers grown with $\mathrm{C} / \mathrm{Si}$ ratios of 1.0 and 1.2 and became the most dominant (1.9

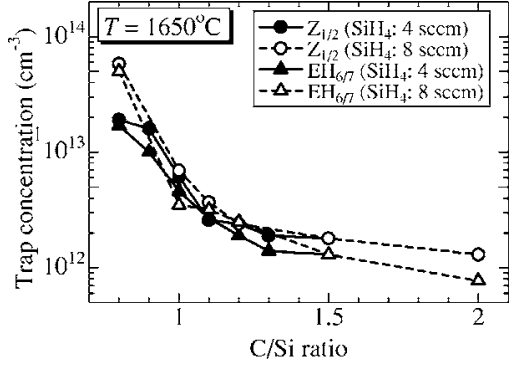

FIG. 2. C/Si ratio dependence of $\mathrm{Z}_{1 / 2}$ and $\mathrm{EH}_{6 / 7}$ concentrations in $4 \mathrm{H}-\mathrm{SiC}$ epilayers grown with a $\mathrm{SiH}_{4}$ flow rate of $4 \mathrm{sccm}$ (growth rate $\sim 14 \mu \mathrm{m} / \mathrm{h}$ ) and $8 \mathrm{sccm}$ (growth rate $\sim 23 \mu \mathrm{m} / \mathrm{h}$ ) at $1650{ }^{\circ} \mathrm{C}$.

$\times 10^{12} \mathrm{~cm}^{-3}$ ) with a $\mathrm{C} / \mathrm{Si}$ ratio of 2.0. As shown in Fig. 1(b), the $\mathrm{UT}_{1}$ concentration tends to increase by increasing the $\mathrm{C} / \mathrm{Si}$ ratio. The center might be related to carbon interstitials, carbon antisites, or silicon vacancies, since they are easily introduced under the C-rich condition. ${ }^{16}$ However, this center could not be observed in the electron-irradiated samples, $8,9,17,18$ in which the defects mentioned earlier will exist in high concentration. Therefore, the $\mathrm{UT}_{1}$ center may relate to a more complicated defect like a defect cluster or a complex, including a defect which is easily introduced under C-rich condition.

Figure 2 shows the $\mathrm{C} / \mathrm{Si}$ ratio dependence of the $\mathrm{Z}_{1 / 2}$ and $\mathrm{EH}_{6 / 7}$ concentrations in epilayers grown at the $\mathrm{SiH}_{4}$ flow rate of 4 and $8 \mathrm{sccm}$ at a fixed growth temperature of $1650{ }^{\circ} \mathrm{C}$. The growth rate was $14 \mu \mathrm{m} / \mathrm{h}$ for a $\mathrm{SiH}_{4}$ flow rate of $4 \mathrm{sccm}$ and $23 \mu \mathrm{m} / \mathrm{h}$ for $8 \mathrm{sccm}$ when the epilayers were grown with a $\mathrm{C} / \mathrm{Si}$ ratio of 1.5 . As shown in Fig. 2, the $\mathrm{Z}_{1 / 2}$ and $\mathrm{EH}_{6 / 7}$ concentrations decreased by more than one order of magnitude when the $\mathrm{C} / \mathrm{Si}$ ratio was changed from 0.8 to 2.0. Interestingly, the $Z_{1 / 2}$ concentration does not depend on the growth rate $(14$ and $23 \mu \mathrm{m} / \mathrm{h})$ as far as the growth was carried out with a given $\mathrm{C} / \mathrm{Si}$ ratio from 1.0 to 1.5 (and at a given temperature of $1650{ }^{\circ} \mathrm{C}$ ). The same tendency is observed for the $\mathrm{EH}_{6 / 7}$ center. In the sample grown with higher growth rate of $54 \mu \mathrm{m} / \mathrm{h}\left(\mathrm{SiH}_{4}\right.$ flow rate $=20 \mathrm{sccm}, \mathrm{C} / \mathrm{Si}$ ratio $=1.0$ or 1.2 , not shown), the trap concentrations (both $\mathrm{Z}_{1 / 2}$ and $\mathrm{EH}_{6 / 7}$ ) were also similar to those in Fig. 2. Therefore, the growth rate does not directly influence the formation of the $\mathrm{Z}_{1 / 2}$ and $\mathrm{EH}_{6 / 7}$ centers and the $\mathrm{C} / \mathrm{Si}$ ratio gives a much larger impact on the defect formation than the growth rate.

Figure 3 shows the DLTS spectra of epilayers grown with a fixed $\mathrm{C} / \mathrm{Si}$ ratio of 1.5 at various temperatures from 1550 to $1750{ }^{\circ} \mathrm{C}$. The growth rate of the samples used for

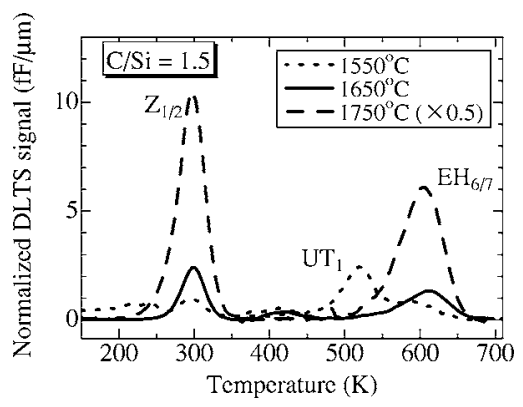

FIG. 3. DLTS spectra of as-grown $n$-type $4 \mathrm{H}$-SiC epilayers grown with a fixed $\mathrm{C} / \mathrm{Si}$ ratio of 1.5 at various temperatures of 1550,1650 , and $1750{ }^{\circ} \mathrm{C}$. 


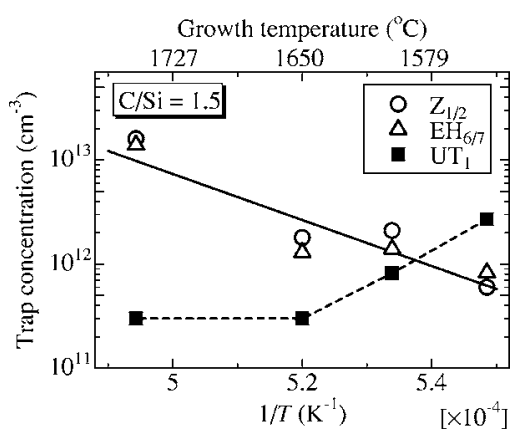

FIG. 4. Arrhenius plot of the $\mathrm{Z}_{1 / 2}, \mathrm{EH}_{6 / 7}$, and $\mathrm{UT}_{1}$ concentrations in the epilayers grown with a fixed $\mathrm{C} / \mathrm{Si}$ ratio of 1.5 . The solid line denotes the least square fit.

this experiment was very close to each other (approximately $14-17 \mu \mathrm{m} / \mathrm{h}$ ). As seen in Fig. 3, the introduction of the $\mathrm{UT}_{1}$ center seems to be enhanced in growth at relatively low temperature. On the other hand, the DLTS signals for the $Z_{1 / 2}$ and $\mathrm{EH}_{6 / 7}$ centers were significantly increased by increasing growth temperature, in good agreement with a previous result obtained in chimney-type CVD at $1740-1840{ }^{\circ} \mathrm{C} .{ }^{19}$ Figure 4 shows the Arrhenius plot of the $\mathrm{Z}_{1 / 2}, \mathrm{EH}_{6 / 7}$, and $\mathrm{UT}_{1}$ concentrations. By increasing growth temperature from 1550 to $1750{ }^{\circ} \mathrm{C}$, the $\mathrm{UT}_{1}$ concentration was decreased from $2.7 \times 10^{12} \mathrm{~cm}^{-3}$ to below the detection limit (about 1-3 $\times 10^{11} \mathrm{~cm}^{-3}$ ). For the $\mathrm{Z}_{1 / 2}$ and $\mathrm{EH}_{6 / 7}$ centers, on the other hand, the trap concentrations were increased from 6.0 $\times 10^{11} \mathrm{~cm}^{-3}$ to $1.6 \times 10^{13} \mathrm{~cm}^{-3}$ for the $\mathrm{Z}_{1 / 2}$ center and from $8.3 \times 10^{11} \mathrm{~cm}^{-3}$ to $1.4 \times 10^{13} \mathrm{~cm}^{-3}$ for the $\mathrm{EH}_{6 / 7}$ center. Therefore, it is effective for reducing the $\mathrm{Z}_{1 / 2}$ and $\mathrm{EH}_{6 / 7}$ concentrations to decrease growth temperature and to increase the $\mathrm{C} / \mathrm{Si}$ ratio.

\section{DISCUSSION}

Storasta et al. reported that the $\mathrm{Z}_{1 / 2}$ and $\mathrm{EH}_{6 / 7}$ centers may be related to carbon displacement [generation of carbon vacancies $\left(V_{\mathrm{C}}\right)$ and carbon interstitials $\left.\left(\mathrm{C}_{i}\right)\right]$ according to their DLTS results on $4 \mathrm{H}-\mathrm{SiC}$ epilayers irradiated with lowenergy $(80-300 \mathrm{keV})$ electrons. ${ }^{17} \mathrm{C}_{i}$ may be thermally much more unstable than $V_{\mathrm{C}}$ due to its high mobility. ${ }^{20,21}$ Considering thermal stability of the centers up to $1500-1600{ }^{\circ} \mathrm{C},{ }^{18,22-24}$ the $\mathrm{Z}_{1 / 2}$ and $\mathrm{EH}_{6 / 7}$ centers may not be $\mathrm{C}_{i}$-related but $V_{\mathrm{C}}$-related defects, which is in agreement with a report by Litton et al. ${ }^{25}$ The authors also made extensive study on the $\mathrm{Z}_{1 / 2}$ and $\mathrm{EH}_{6 / 7}$ centers in $4 \mathrm{H}-\mathrm{SiC}$ epilayers irradiated with low-energy electrons and speculated that both centers may originate from a same defect, probably containing $V_{\mathrm{C}}{ }^{18}$ The formation of $V_{\mathrm{C}}$ is suppressed under C-rich condition and enhanced under Si-rich condition. This may be the reason why the $\mathrm{Z}_{1 / 2}$ and $\mathrm{EH}_{6 / 7}$ concentrations were decreased under $\mathrm{C}$-rich condition.

According to a simple model on the formation of vacancies in solids, ${ }^{26}$ the concentration of neutral carbon vacancies $\left(N_{V_{\mathrm{C}}}\right)$ in thermal equilibrium is given by

$$
N_{V_{\mathrm{C}}}=N_{0} \exp \left(\frac{\Delta S}{k}\right) \exp \left(-\frac{\Delta H}{k T}\right)=A \exp \left(-\frac{\Delta H}{k T}\right)
$$

where $N_{0}$ is the concentration of C lattice sites, $\Delta S$ the effective entropy of formation of neutral carbon vacancy, $k$ the Boltzmann constant, $\Delta H$ the effective enthalpy of formation (formation energy) of neutral carbon vacancy, $T$ the absolute temperature, and $A$ the constant. From the slope of the Arrhenius plot shown in Fig. 4, the activation energies for formation of the $\mathrm{Z}_{1 / 2}$ and $\mathrm{EH}_{6 / 7}$ centers were estimated to be $4.6 \pm 0.3 \mathrm{eV}$, which shows agreement with the formation energy calculated for $V_{\mathrm{C}}$ in $4 \mathrm{H}-\mathrm{SiC}$ [for example, $4.41-4.49 \mathrm{eV}$ (Ref. 16) and $5.48 \mathrm{eV}$ (Ref. 27)]. The obtained activation energy is also close to those obtained for $n$-type epilayers grown by chimney-type hot-wall CVD at $1740-1840{ }^{\circ} \mathrm{C}$ (4.3 eV for the $\mathrm{Z}_{1 / 2}$ center and $4 \mathrm{eV}$ for the $\mathrm{EH}_{6 / 7}$ center). ${ }^{19}$ Thus, the increase in the $\mathrm{Z}_{1 / 2}$ and $\mathrm{EH}_{6 / 7}$ concentrations with increasing growth temperature follows the same tendency as the equilibrium $V_{\mathrm{C}}$ concentration in $\mathrm{SiC}$. If the $\mathrm{Z}_{1 / 2}$ and $\mathrm{EH}_{6 / 7}$ centers are attributed to or contain $V_{\mathrm{C}},{ }^{17,18}$ the high trap concentration in epilayers grown at high temperature may be reasonably understood. On the other hand, the $\mathrm{UT}_{1}$ center does not follow this trend, probably because the $\mathrm{UT}_{1}$ center may originate from a completely different defect complex.

\section{SUMMARY}

In summary, the authors investigated impacts of CVD parameters on deep levels in as-grown $n$-type $4 \mathrm{H}$-SiC. The formation of $\mathrm{Z}_{1 / 2}$ and $\mathrm{EH}_{6 / 7}$ centers were governed mainly by the $\mathrm{C} / \mathrm{Si}$ ratio and growth temperature rather than the growth rate. The $\mathrm{C}$-rich condition is favorable to suppress the formation of the $\mathrm{Z}_{1 / 2}$ and $\mathrm{EH}_{6 / 7}$ centers. This is probably because both the centers are $V_{\mathrm{C}}$-related defects. The $\mathrm{Z}_{1 / 2}$ and $\mathrm{EH}_{6 / 7}$ concentrations were increased by increasing growth temperature in a similar manner to the temperature dependence of concentration of neutral $V_{\mathrm{C}}$ in thermal equilibrium. Therefore, it is important to choose the proper $\mathrm{C} / \mathrm{Si}$ ratio and growth temperature (relatively high $\mathrm{C} / \mathrm{Si}$ ratio from a stoichiometric point and not too high growth temperature) in order to grow high-quality epilayers at high growth rate. The $\mathrm{UT}_{1}$ center could be detected in the epilayers grown with a high $\mathrm{C} / \mathrm{Si}$ ratio and/or a low growth temperature.

\section{ACKNOWLEDGMENTS}

This work was financially supported in part by a Grandin-Aid for the Fundamental Research (No. 18206032) and the 21st century COE program (No. 1421320) from the Ministry of Education, Culture, Sports, Science and Technology, Japan.

${ }^{1}$ M. Bhatnagar and B. J. Baliga, IEEE Trans. Electron Devices 40, 645 (1993).

${ }^{2}$ H. Lendenmann, F. Dahlquist, J. P. Bergman, H. Bleichner, and C. Hallin, Mater. Sci. Forum 389-393, 1259 (2002).

${ }^{3}$ Y. Sugawara, D. Takayama, K. Asano, A. Agarwal, S. Ryu, J. Palmour, and S. Ogata, Proceedings of the International. Symposium on Power Semiconductor Devices \& ICs 2004, Kitakyusyu, 2004, pp. 365-368.

${ }^{4}$ J. P. Bergman et al., Mater. Sci. Forum 389-393, 9 (2002).

${ }^{5}$ T. Tawara, H. Tsuchida, S. Izumi, I. Kamata, and K. Izumi, Mater. Sci. 
Forum 457-460, 565 (2004)

${ }^{6}$ K. Danno, K. Hashimoto, H. Saitoh, T. Kimoto, and H. Matsunami, Jpn. J. Appl. Phys., Part 2 43, L969 (2004).

${ }^{7}$ P. B. Klein, B. V. Shanabrook, S. W. Huh, A. Y. Polyakov, M. Skowronski, J. J. Sumakeris, and M. J. O'Loughlin, Appl. Phys. Lett. 88, 052110 (2006).

${ }^{8}$ T. Dalibor, G. Pensl, H. Matsunami, T. Kimoto, W. J. Choyke, A. Schöner, and N. Nordell, Phys. Status Solidi A 162, 199 (1997).

${ }^{9}$ C. Hemmingsson, N. T. Son, O. Kordina, J. P. Bergman, E. Janzén, J. L. Lindström, S. Savage, and N. Nordell, J. Appl. Phys. 81, 6155 (1997).

${ }^{10}$ D. V. Lang, J. Appl. Phys. 45, 3023 (1974).

${ }^{11}$ K. Fujihira, T. Kimoto, and H. Matsunami, J. Cryst. Growth 255, 136 (2003).

${ }^{12}$ T. Kimoto, K. Hashimoto, and H. Matsunami, Jpn. J. Appl. Phys. 42, 7294 (2003).

${ }^{13}$ T. Kimoto, S. Nakazawa, K. Hashimoto, and H. Matsunami, Appl. Phys. Lett. 79, 2761 (2001).

${ }^{14}$ S. Weiss and R. Kassing, Solid-State Electron. 31, 1733 (1988).

${ }^{15}$ S. D. Brotherton, Solid-State Electron. 26, 987 (1983).

${ }^{16}$ L. Torpo, M. Marlo, T. E. M. Staab, and R. M. Nieminen, J. Phys.: Condens. Matter 13, 6203 (2001).

${ }^{17}$ L. Storasta, J. P. Bergman, E. Janzén, A. Henry, and J. Lu, J. Appl. Phys.
96, 4909 (2004)

${ }^{18}$ K. Danno and T. Kimoto, J. Appl. Phys. 100, 113728 (2006).

${ }^{19}$ J. Zhang, L. Storasta, J. P. Bergman, N. T. Son, and E. Janzén, J. Appl. Phys. 93, 4708 (2003).

${ }^{20}$ M. Bockstedte, A. Mattausch, and O. Pankratov, in Silicon Carbide, Recent Major Advances, edited by W. J. Choyke, H. Matsunami, and G. Pensl (Springer, Berlin, 2003), pp. 27-55.

${ }^{21}$ F. Gao, W. J. Weber, M. Posselt, and V. Belko, Mater. Sci. Forum 457-460, 457 (2004).

${ }^{22}$ L. Storasta, F. H. C. Carlsson, S. G. Sridhara, J. P. Bergman, A. Henry, T. Egilsson, A. Hallen, and E. Janzén, Appl. Phys. Lett. 78, 46 (2001).

${ }^{23}$ A. Kawasuso, M. Weidner, F. Redmann, T. Frank, P. Sperr, R. KrauseRehberg, W. Triftshäuser, and G. Pensl, Physica B 308-310, 660 (2001).

${ }^{24}$ Y. Negoro, T. Kimoto, and H. Matsunami, Appl. Phys. Lett. 85, 1716 (2004).

${ }^{25}$ C. W. Litton, D. Johnstone, S. Akarca-Biyikli, K. S. Ramaiah, I. Bhat, T. P. Chow, J. K. Kim, and E. F. Schubert, Appl. Phys. Lett. 88, 121914 (2006).

${ }^{26}$ F. A. Kröger, The Chemistry of Imperfect Crystals (North-Holland, Amsterdam, 1964), Vol. 2, p. 146

${ }^{27}$ F. Gao, E. J. Bylaska, W. J. Weber, and L. R. Corrales, Phys. Rev. B 64, 245208 (2001) 